\title{
FORMATION AND DEVELOPMENT OF SUBMERGED AIR JETS
}

\author{
Sultana R. Syeda* and Ashfaq M. Ansery \\ Department of Chemical Engineering \\ Bangladesh University of Engineering and Technology, Dhaka -1000, Bangladesh \\ *Corresponding e-mail: syedasrazia@che.buet.ac.bd
}

\begin{abstract}
An experimental investigation on submerged air jets was carried out in a $14 \times 14 \mathrm{~cm}^{2}$ perspex column with a liquid height of $25 \mathrm{~cm}$. Jets were generated by flowing air at different velocities through nozzles immersed at the bottom of a stagnant liquid pool. The diameters of the nozzles used were 1, 4 and $6 \mathrm{~mm}$. The jet formation was observed in three different liquids; namely, water, ethanol and glycerol. The jet formation velocity and jet lengths at different liquids and with different nozzles were measured by video recording and image processing. Two distinct regime transitions; bubbling to jetting and jetting to bubble plume were observed. The jet length increased steadily with jet velocity. The nozzle size was found to affect both jet formation and jet length. The properties of liquid also affect the formation of jet.
\end{abstract}

Keywords: Submerged air jet, Regime transition, Bubble to jet transition, Bubble plume.

\section{INTRODUCTION}

By using submerged gas jets heat and mass transfer rates are sometimes enhanced in varieties of applications; e.g. nuclear reactors, metallurgical processes, oxygenators of pharmaceutical industries, stored chemical energy propulsion systems for underwater applications, etc. Studies of submerged gas jets started in the later part of the twentieth century with the advent of these applications. A gas jet formed by injection of a gas into a liquid pool consists of a gas core, either bubbling or jetting, and a liquid circulating zone around the gas core. Depending on the gas velocity, a two-phase turbulent zone of gas-liquid dispersion may exist between the gas core and the liquid circulating zone ${ }^{1}$. Formation of jet as well as jet length in submerged condition depends on a number of factors such as gas velocity, nozzle geometry, liquid properties, size and depth of the liquid column, etc.,3

The theoretical studies dealing with submerged gas jets focused mostly on stability analysis of gas jets in terms of the disturbance generated on the jet surface ${ }^{4,5}$. Koria $^{6}$ calculated the non-buoyant jet length of gas jets in a metal bath for both subsonic and supersonic regions. Chen and Richter ${ }^{1}$ studied the instability of a circular compressible gas jet in an inviscid liquid. These analytical studies explored different conditions that may exist in the surrounding of a gas jet and affect the jet length.

The experimental studies, on the other hand, largely dealt with transition from bubble to jet. Ruzicka et al. ${ }^{7}$ used a gas jet issued by an orifice at the bottom of a pool of stagnant liquid to study its transition from bubbling to jetting regime in a nitrogen-water system. Sundar and $\operatorname{Tan}^{8}$ carried out a similar study on air/water and air/kerosene systems with low liquid height (4-6 $\mathrm{cm})$. They used an optical fibre probe to measure the time-averaged void fraction to characterize the transition from bubbling to jetting. This study is in line with earlier studies dealing with froth to spray transition on sieve trays of distillation or absorption columns where very low liquid height rather than liquid pool was used ${ }^{9}$. Iguchi et al. ${ }^{10}$ studied the flow field of a vertical bubbling jet in a cylindrical vessel. They proposed empirical correlations for bubble frequency and gas holdup in the momentum region of an air-water vertical bubbling jet. Later, Iguchi et al. ${ }^{11}$ investigated bubble behavior in the buoyancy region by means of electro-resistivity probes, a high-speed video camera, and a laser Doppler velocimeter and developed correlations for gas holdup, bubble frequency and bubble rising velocity as functions of gas flow rate. Rensen and Roig ${ }^{12}$ studied the behavior of the flow in two dimensional bubble plumes confined in a tank using an optical probe and a video camera.

However, none of the above-mentioned papers reported experimental data of jet length. As mentioned earlier the application of submerged gas jets in different modern industrial processes is increasing. To better understand the behaviour of submerged gas jets, Ansery ${ }^{13}$ carried out a thorough experimental study on the variation of jet length with nozzle geometry and physical properties of the liquids. This paper reports the experimental data of submerged air jets and interprets the experimental findings according to the current theoretical understanding. Air jets issuing from submerged nozzles were studied by video recording and image analysis. Experiments were done with nozzles of three different diameters, three different liquids and various flow conditions. The regime transition of air jets was observed and the effects of jet velocity, nozzle diameter and liquid properties on the formation and development of an air jet have been investigated. 


\section{EXPERIMENTAL SET-UP AND PROCEDURE}

A schematic diagram of the experimental set-up is given in Figure 1. The set-up includes a liquid chamber, a compressed air supply, an air releasing nozzle, a length measuring scale, a rotameter and a video imaging system. The liquid chamber was made up of a perspex column having dimensions $14 \mathrm{~cm} \times 7 \mathrm{~cm}$ $x 30 \mathrm{~cm}$. It was filled with liquid to a height of $25 \mathrm{~cm}$. The jets were generated by flowing air through the nozzle at the bottom of the chamber immersed in stagnant liquid. The fluctuation in air flow rate was minimized by placing an air vessel between the compressor and the rotameter. Three different nozzles made of smooth commercial copper pipe of 1,4 and 6 $\mathrm{mm}$ diameter were used. The experiments were carried out in room condition with three different liquids, namely, water, ethanol and glycerol. The temperature of the liquids during the experiments was $30 \pm 2^{\circ} \mathrm{C}$.
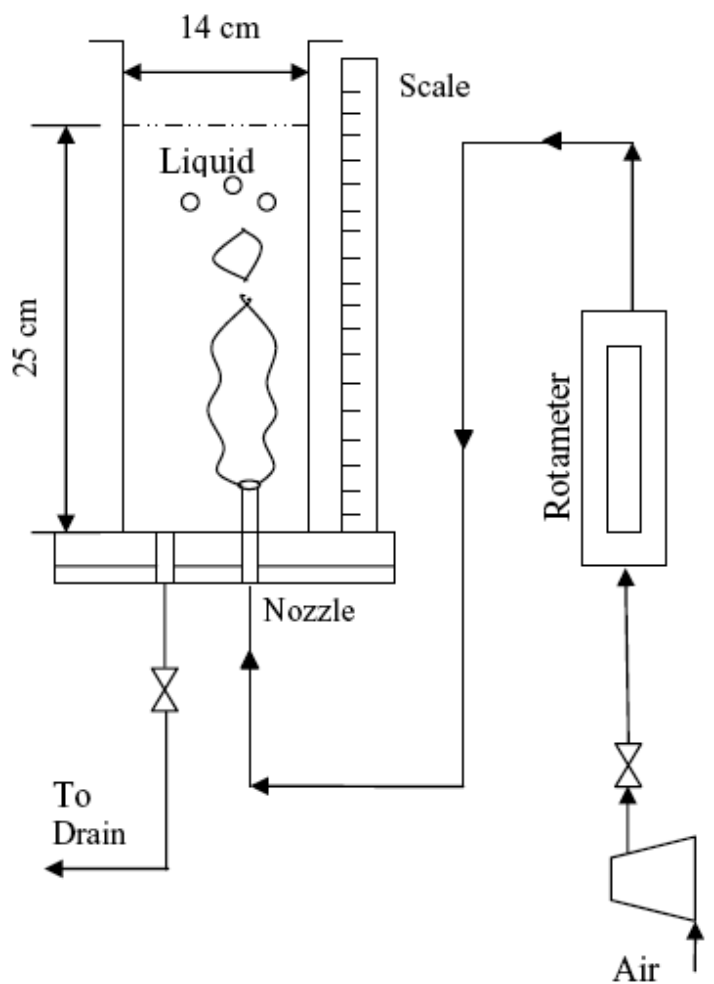

Figure 1. Schematic diagram of the experimental set-up.

Jet Length Measurement

A digital video system (Sony, Model DMV-60) was used to record the video image of the jet at 60 frames per sec. The video image was used to measure the length of the gas jets in liquids. At a steady air flow rate, video clips of the jets were saved in a computer and split into individual frames to get still images. Out of these, the best five frames were selected that clearly showed both the jet boundaries and the scale attached in the experimental set up. The length of the jet was then read from the scale. Average of the five readings was taken as the length of the jet and approximately $\pm 7 \%$ uncertainty was observed in the measured jet length.

\section{Jet Velocity Measurement}

Jet velocity was calculated from the air flow rate measured by a rotameter and the cross sectional area of the nozzle. The rotameter was calibrated for a range of $10 \mathrm{lit} / \mathrm{hr}\left(2.78 \mathrm{~cm}^{3} / \mathrm{s}\right)$ to $360 \mathrm{lit} / \mathrm{hr}\left(100 \mathrm{~cm}^{3} / \mathrm{s}\right)$ using a standard wet test meter and a stop watch. The air flow rate was determined with approximately $\pm 5 \%$ uncertainty. The maximum flow rate used in the experiment was $300 \mathrm{lit} / \mathrm{hr}\left(83.33 \mathrm{~cm}^{3} / \mathrm{s}\right)$. Any flow rate higher than this caused large fluctuation in jet length and hence measurement could not be made. For the air/glycerol system, foaming occurred while air passed through the liquid making the liquid chamber opaque; thus limited data were obtained for this system at low flow rates. Furthermore, lots of tiny bubbles formed on the surface of the jet issued from the $1 \mathrm{~mm}$ nozzle made it difficult to measure unbroken jet length beyond an air flow rate of $40 \mathrm{~cm}^{3} / \mathrm{s}$. Therefore, the maximum flow rate applied for the $1 \mathrm{~mm}$ nozzle was $40 \mathrm{~cm}^{3} / \mathrm{s}$.

\section{RESULTS AND DISCUSSION \\ Flow regime transition}

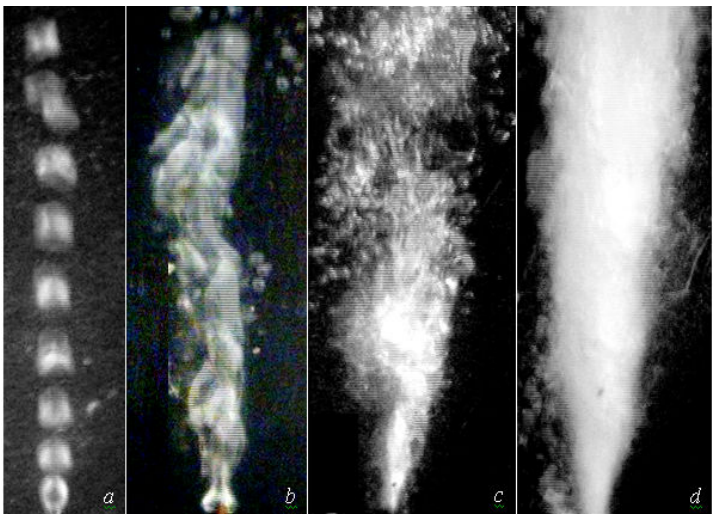

Figure 2. Different flow regimes of an air jet in ethanol issued from a $1 \mathrm{~mm}$ nozzle at a) $\mathrm{U}=800 \mathrm{~cm} / \mathrm{s}$; b) $U=1800 \mathrm{~cm} / \mathrm{s}$; c) $U=4500 \mathrm{~cm} / \mathrm{s}$; d) $U=7000 \mathrm{~cm} / \mathrm{s}$ (the figures are not in the same scale)

As air was passed though the nozzle a number of flow regimes were observed with the increase of air jet velocity, U. Figure 2 presents different flow regimes of an air jet in ethanol for the $1 \mathrm{~mm}$ nozzle. Two distinct transitions of the regimes occurred as the velocity was increased. The first transition was from discrete bubbles to jet and the second one was from jet to bubble plume. At a low velocity, discrete bubbles formed at the nozzle and a chain of bubbles was observed in the liquid chamber as seen in figure 2(a). At a jet velocity 
of $1800 \mathrm{~cm} / \mathrm{s}$, the frequency of bubbles became high enough to form into a jet. Figure 2(b) shows a developed air jet. The jet length increased with the increase of air jet velocity. At large jet velocities, (say at more than $3500 \mathrm{~cm} / \mathrm{s}$ ), small bubbles started forming on the jet surface. As the jet velocity increased beyond $6000 \mathrm{~cm} / \mathrm{s}$, the bubble swarm surrounding the jet made the jet boundaries undetectable. A further increase in jet velocity led to formation of complete bubble plume. Figure 2(c) shows the jet at $4500 \mathrm{~cm} / \mathrm{s}$ when bubbles were formed on the jet surface at a significant number and transition from jet to bubble plume occurred. Figure 2(d) was taken at an air jet velocity, $U=7000$ $\mathrm{cm} / \mathrm{s}$ when the air jet completely converted to a bubble plume. These flow regimes were observed also in water for air jets issued with a $1 \mathrm{~mm}$ nozzle.

With $4 \mathrm{~mm}$ and $6 \mathrm{~mm}$ nozzles, the first transition, i.e. transition from bubble to jet occurred at a much lower velocity. The jet length steadily increased with air jet velocity. As the experiment was limited to $83.33 \mathrm{~cm}^{3} / \mathrm{s}$ of air flow rate, the highest velocities achieved for 4 and $6 \mathrm{~mm}$ nozzles were far smaller than that for the 1 $\mathrm{mm}$ nozzle. Within the velocity range, the bubble swarming at the jet surface was insignificant. As a result, only the first transition from bubble to jet was observed and the second transition, i.e. the transition from jet to bubble plume could not be reached. Above observation was made for both air/water and air/ethanol systems. As mentioned earlier, excessive foaming occurred in air/glycerol system even at low velocity. Therefore, fewer jet length data were obtained for this system.

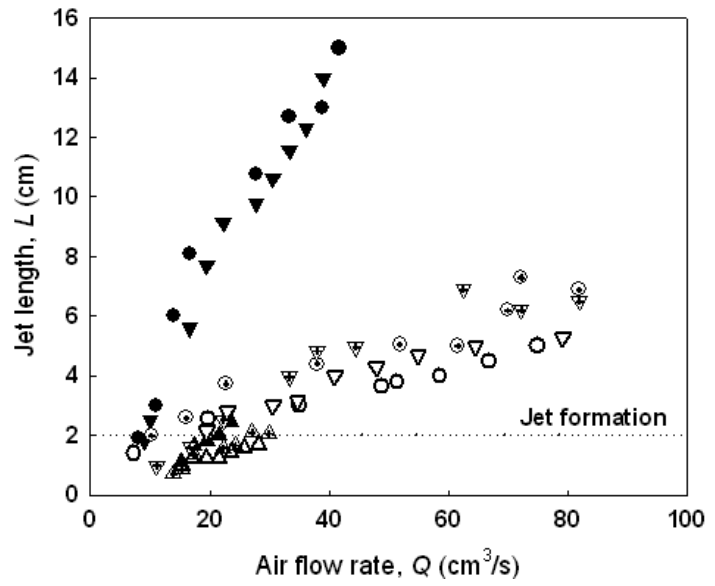

Figure 3. Jet length versus air flow rate in different liquids and for different nozzles.

(Black symbols indicate $1 \mathrm{~mm}$ nozzle, crossed symbols indicate $4 \mathrm{~mm}$ nozzle and open symbols indicate $6 \mathrm{~mm}$ nozzle. Circles indicate air/ethanol system, downward triangles indicate air/water system and upward triangles indicate air/glycerol system.)

\section{Jet Length}

Figure 3 shows how the measured values of jet length vary with increasing air flow rate in different liquids and for different nozzles. As the bubble to jet transition is reached with the increase of air flow rate, several bubbles merge together to form an air jet. It is arbitrarily considered that a jet is 'formed' if its length is longer than $2 \mathrm{~cm}$. The velocity of jet at this length is taken as jet formation velocity, u. Figure 4 gives the plots of jet length, L with respect to jet velocity, $U$. The figure shows that the smaller the nozzle size, the higher is the jet formation velocity. For example, the jet formation velocity in the 4 and $6 \mathrm{~mm}$ nozzles is in the range of $60-200 \mathrm{~cm} / \mathrm{s}$ whereas that in the $1 \mathrm{~mm}$ nozzle is in the range of $1500 \mathrm{~cm} / \mathrm{s}$ to $2000 \mathrm{~cm} / \mathrm{s}$.

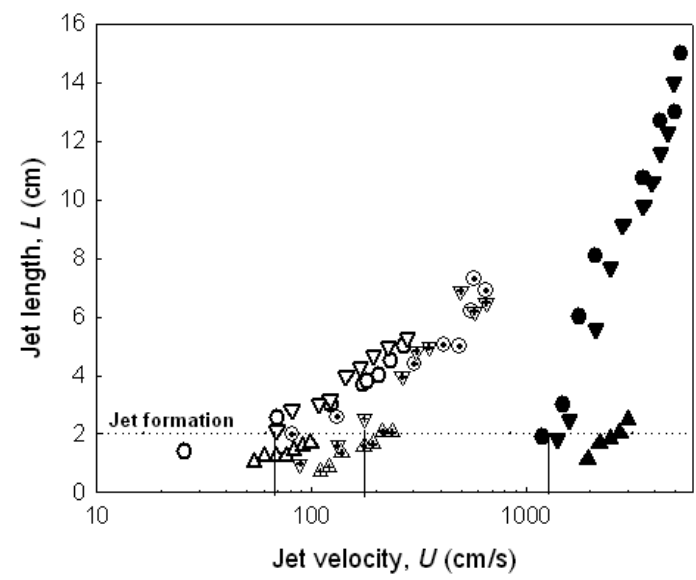

Figure 4. Jet formation velocities for different nozzles. (Black symbols indicate $1 \mathrm{~mm}$ nozzle, crossed symbols indicate $4 \mathrm{~mm}$ nozzle and open symbols indicate $6 \mathrm{~mm}$ nozzle. Circles indicate air/ethanol system, downward triangles indicate air/water system and upward triangles indicate air/glycerol system.)

Formation of a jet, i.e. transition from bubbling to jetting is a much studied phenomenon. A number of empirical and semi-empirical correlations for bubble to jet transition velocity are available in literature. It has been shown in literature that the jet formation velocity, $\mathrm{u}$ depends on nozzle diameter, $\mathrm{D}$, height of the liquid pool, $\mathrm{H}$ and the properties of the gas and the liquid. Following are two correlations by Sundar and $\operatorname{Tan}^{8}$ and Lockett $^{9}$, respectively:

$$
\begin{aligned}
& \frac{H}{D}=C_{1}\left(\frac{u \rho_{G}^{0.5}}{\left[\sigma g\left(\rho_{L}-\rho_{G}\right)\right]^{0.25}}\right)+C_{2} \\
& \frac{H}{D}=C\left(\frac{\rho_{G}}{\rho_{L}}\right)^{0.5} u
\end{aligned}
$$

In these equations $\mathrm{C}, \mathrm{C}_{1}$ and $\mathrm{C}_{2}$ are constants to be determined by experiments, $\sigma$ is the interfacial tension 
and $\rho_{\mathrm{L}}$ and $\rho_{\mathrm{G}}$ are densities of the liquid and the gas, respectively. Both of these equations were validated by experimental data with small liquid height. These equations show that bubble to jet transition velocity, i.e. the jet formation velocity increases with decreasing nozzle size, which agrees qualitatively with the present observation. Any quantitative analysis would require considerations of other geometric factors such as large liquid height, smoothness of nozzle etc.

As mentioned earlier, the reported theoretical analyses of submerged gas jets, particularly the phenomena of the transition from bubbling to jetting and jet break-up are mainly based on the instability of an air jet in a liquid. According to these analyses, disturbances occur at the surface of the submerged gas jet due to aerodynamic drag caused by the relative motion between the gas and the liquid. These disturbances generate instability on the surface of the gas jet and the jet eventually breaks off.

A number of theoretical analyses show that at low Mach number (less than 0.1 ) the growth rate of surface disturbance is constant with respect to jet velocity, $U$ and hence, jet length, $\mathrm{L}$ is a linear function of $U^{1,5}$. The Mach number of the jets in the present study is very small (less than 0.01) and the plots of L vs $U$ are expected to be straight lines through the origin.

\section{Effect of Nozzle Size}

Figures 5(a), (b) and (c) present the plots of jet length versus jet velocity in three liquids for $1 \mathrm{~mm}, 4$ $\mathrm{mm}$ and $6 \mathrm{~mm}$ nozzles, respectively. For the three nozzles jet length increased steadily with jet velocity. The figures give the best fitted straight lines through the origin for the data in water and ethanol. The slopes of the lines for 6 and $4 \mathrm{~mm}$ nozzles are found to be of order $10^{-2} \mathrm{~s}$. whereas for $1 \mathrm{~mm}$ nozzle it is of order $10^{-3}$ $\mathrm{s}$. This difference in slopes implies that the jet length is affected not only by jet velocity but also by factors like nozzle roughness, nozzle diameter, etc.

Table 1. Jet formation velocity at different nozzle diameters and liquid properties, $\sigma / \mu_{\mathrm{L}}$.

\begin{tabular}{|c|c|c|c|c|}
\hline \multirow{2}{*}{ Liquid } & \multirow{2}{*}{$\begin{array}{c}\boldsymbol{\sigma} \boldsymbol{\mu}_{\boldsymbol{L}} \\
(\mathrm{cm} / \mathrm{s})\end{array}$} & \multicolumn{3}{|c|}{ Jet formation velocity $\boldsymbol{u}$} \\
\cline { 3 - 5 } & & $\begin{array}{c}1 \mathrm{~mm} \\
\text { nozzle }\end{array}$ & $\begin{array}{c}4 \mathrm{~mm} \\
\text { nozzle }\end{array}$ & $\begin{array}{c}6 \mathrm{~mm} \\
\text { nozzle }\end{array}$ \\
\hline Water & 7290 & 1400 & 130 & 70 \\
\hline Ethanol & 1841 & 1200 & 80 & 50 \\
\hline Glycerol & 4.2 & - & - & - \\
\hline
\end{tabular}

\section{Effect of Liquid Properties}

The plots in Fig. 5 also show that for air/glycerol system the jet was not formed under the present experimental conditions. Although limited data were taken for this system, a comparison with other systems show that at the velocity at which well developed jets
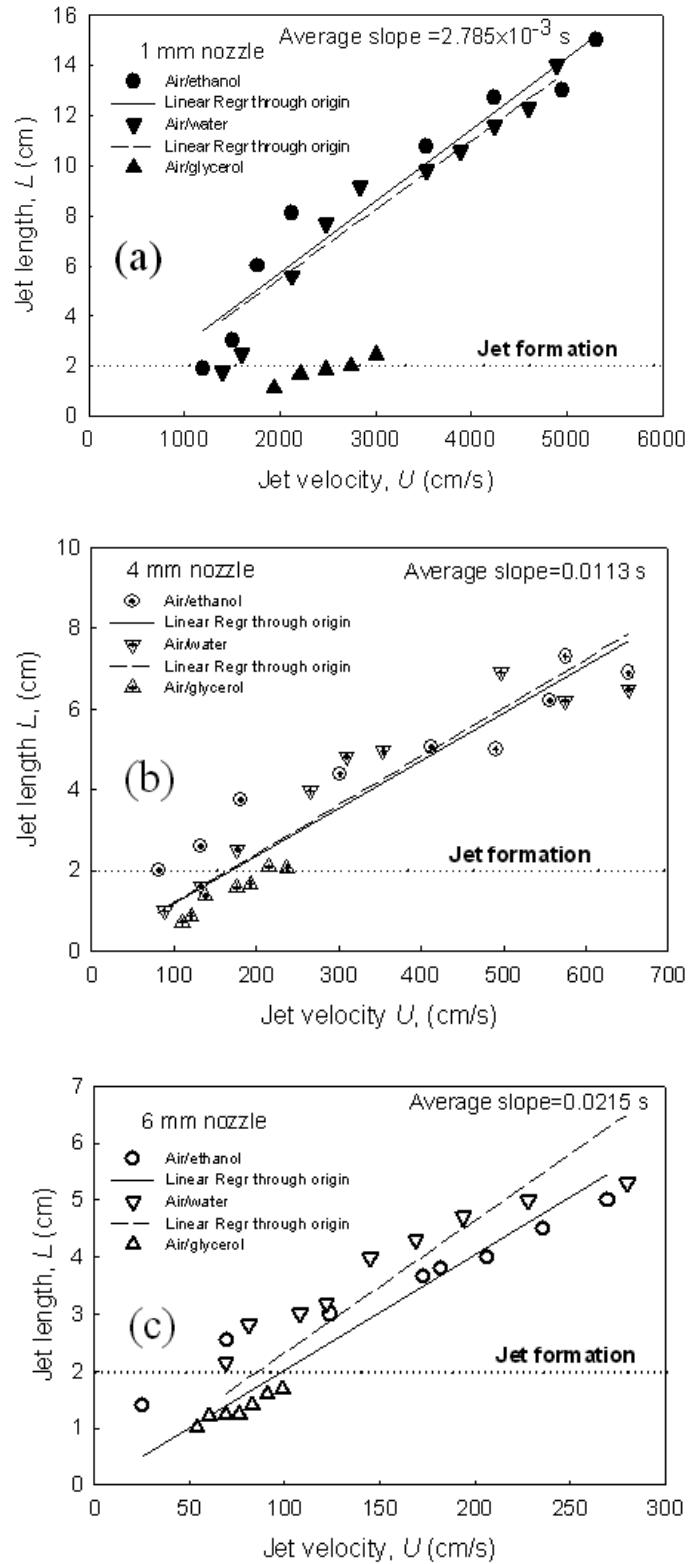

Figure 5. Plots of jet length versus jet velocity fitted in straight lines through origin for a) $1 \mathrm{~mm}$, b) $4 \mathrm{~mm}$ nozzle and c) $6 \mathrm{~mm}$ nozzle.

were observed in water or ethanol, only discrete air bubbles were observed in glycerol. This is particularly true for the $1 \mathrm{~mm}$ nozzle. Chan et al. ${ }^{5}$ showed that when viscosity of the liquid is larger than its surface tension, the disturbance on the surface of the submerged gas jet grows fast and early break-up of the jet occurs. Thus, surface tension to viscosity ratio, $\sigma / \mu_{\mathrm{L}}$, of a liquid has major effect on jet formation. As surface tension force tends to restore the jet and viscosity tries to break it off, the larger the ratio of $\sigma / \mu_{\mathrm{L}}$, the larger is the jet formation velocity. Table 1 shows that the jet formation velocities in the three liquid systems follow the trend of the $\sigma / \mu_{\mathrm{L}}$ values of the liquids. 


\section{CONCLUSIONS}

The present work experimentally investigates the effects of jet velocity, nozzle size and liquid properties on the formation and development of an air jet submerged in a stagnat liquid pool. New experimental data of jet lengths versus jet velocities are presented here for three gas/liquid systems. It is shown that the nozzle size and the physical properties of liquids have significant impact on the jet length as well as on the regime of the gas jets. The findings of the present study can be summarized as follows

- Two regime transitions from bubble to jet and jet to bubble plume occur as the velocity of submerged gas jet increases.

- Gas jet is formed at larger velocity for smaller nozzle size.

- Jet length can be considered as a linear function of jet velocity at low Mach number.

- Formation of gas jets is impeded in liquids with large viscosity.

\section{REFERENCES}

1. Chen K., Richter H.J., 1997. Instability analysis of the transition from bubbling to jetting in a gas injected into a liquid. Int. J. Multiphase Flow 23, 699-712.

2. Ansery A. M., Syeda S. R., 2008. Effect of jet velocity and nozzle size on stability of submerged air jet, Proc. 2nd Int. Conf. of Chemical Engineering, 29-30 December, Dhaka, Bangladesh, 4-8.

3. Hasan, M. M. F., Islam A. M. W., Syeda S. R., 2005. Formation and disintegration of air jet in liquids", Proc. $5^{\text {th }}$ IMEC conf. and $10^{\text {th }}$ Annual Paper Meet, 30 Sept.-2 Oct, Dhaka , Bangladesh, 160-164.

4. Chawla T.C., 1975. The Kelvin-Helmholtz instability of the gas-liquid interface of a sonic gas jet submerged in a liquid. J. Fluid Mech. 67, 513-537.
5. Chan S. H., Wang Y. S., Tan C. C., 1994. The effect of mass transfer on Kelvin-Helmholtz instability at the gas- liquid interface of a sonic reacting and non-reacting gas jet submerged in a liquid. Int. J. Heat Mass Transfer. 37(7), 1123 - 1132.

6. Koria S.C., 1993. Principles and applications of gas injection in steel making practice. Scandinavian, J. Metall. 22, 271-279.

7. Ruzicka M. C., Drahos J., Zahradnik J., Thomas N. H., 1997. Intermittent transition from bubbling to jetting regime in gas-liquid two phase flows. Int. J. Multiphase Flow, 23(4), $671-682$.

8. Sundar R., Tan R. B. H., 1999. A model for bubble-to-jet transition at a submerged orifice. Chem. Eng. Sci. 54 (18), 4053-4060.

9. Lockett M. J., 1981. The froth to spray transition on sieve trays. Chem. Eng. Res. and Des. 59a, 26-34.

10. Iguchi M., Nozawa K., Morita Z., 1991. Bubble characteristics in the momentum region of air-water vertical bubbling jet, ISIJ International, 31 (9), 952 959.

11. Iguchi M., Nozawa K., Tomida H., Morita Z., 1992. Bubble characteristics in the buoyancy region of a vertical bubbling jet, ISIJ International, 32 (6), 747 754.

12. Rensen J., Roig, V, 2001. Experimental study of the unsteady structure of a confined bubble plume. Int. J. Multiphase Flow, 27, 1431 - 1449.

13. Ansery A. M., 2009. Study of submerged air jets in liquids, M. Sc. in Chemical Engineering thesis, Department of Chemical Engineering, BUET, Dhaka 1000, Bangladesh. 